\title{
Arquitetura de escolhas nas escolas: um empurrão para a melhoria da educação
}

\author{
Adriana Spacca Olivares Rodopoulos é economista e especialista \\ em Psicologia Econômica pela Pontifícia Universidade Católica de \\ São Paulo (PUC-SP). Integra o Grupo de Estudos sobre Psicología \\ Econômica conduzido pela Dra. Vera R. de M. Ferreira e atua \\ como coach nas áreas educacional e familiar.
}

Nudge: o empurrão para a escolha certa, de Richard H. Thaler - professor emérito de Ciência Comportamental e Economia e também diretor do Centro de Pesquisa sobre Decisões da Escola de Pós-Graduação em Negócios da Universidade de Chicago - e Cass R. Sunstein - professor emérito de Jurisprudência da Escola de Direito e do Departamento de Ciências Políticas da Universidade de Chicago -, apresenta ao leitor a emergente ciência das escolhas, segundo eles, "constituída por pesquisas cuidadosas realizadas por cientistas sociais ao longo das últimas quatro décadas. Essas pesquisas levantaram questões sérias sobre a racionalidade de muitos julgamentos e decisões feitos pelas pessoas" (p. 7). Dividido em cinco partes, o livro tem sua primeira seção dedicada à introdução dos pilares e do conceito da arquitetura de escolhas; as demais contêm sugestões e exemplos de aplicação (inclusive em termos de políticas públicas) ligados a temas como dinheiro, saúde, liberdade, dentre outros.

Inicialmente, os autores fazem uma crítica ao modelo econômico vigente baseado no funcionamento mental do Homo economicus, um ser capaz de fazer escolhas infalivelmente boas em razão da racionalidade e da imparcialidade como sendo as únicas características do raciocínio humano. Nesse sentido, muitas escolas também organizam suas condutas a partir de um modelo de racionalidade e imparcialidade ideais em que alunos e professores sempre tomam as melhores decisões com relação à aprendizagem e pais atuam como se fossem integralmente responsáveis por seus filhos. De acordo com tal modelo, à semelhança do que ocorre na economia, aquilo que foge ao padrão é tratado como anomalia.

Já a economia comportamental e a psicologia econômica 
baseiam seus modelos no Homo sapiens, ou seja, nas pessoas de verdade, que estão sujeitas a cometer uma série de erros grosseiros de julgamento devido ao próprio funcionamento cerebral humano, o qual seria regido por dois sistemas: 0 sistema automático e o sistema reflexivo, também chamados, respectivamente, de sistema 1 e sistema 2. "Essa abordagem envolve uma distinção entre dois tipos de raciocínio: um é intuitivo e automático, enquanto o outro é reflexivo e racional" (p. 21). Um comportamento considerado anômalo - tanto em economia quanto em algumas escolas - é visto, nessa perspectiva, como produto do interjogo entre os dois sistemas a que todos estamos sujeitos, em qualquer área da vida.

Segundo Thaler e Sunstein, estamos mais suscetíveis a cometer erros quando:

1. Temos de fazer escolhas em áreas nas quais não somos especialistas - vale ressaltar que a familiaridade não nos torna necessariamente especialistas. Um exemplo dessa situação, segundo minha observação, é que, apesar de a escola ser um ambiente altamente familiar para pais e alunos, isso não os torna especialistas em educação.

2. As consequências de nossas escolhas não são imediatas, ou seja, o feedback é lento. De acordo com o que observo, em escolas onde a avaliação é pontual, alunos e pais normalmente recebem feedback sobre resultado (e raramente sobre percurso) a cada três meses.

2. Temos dificuldade em mapear as opções, isto é, em traduzir informações complexas. Não é muito difícil perceber que os documentos escolares sobre regimento interno são um bom exemplo de informações complexas para pais e alunos.

De acordo com os pressupostos da economia (e de algumas escolas), quando as pessoas se deparam com tais situações, espera-se que elas utilizem a racionalidade do sistema 2 para avaliar imparcialmente todas as alternativas e tomar uma decisão ótima. Entretanto, o que de fato ocorre é que, quando expostos a essas situações, tomamos atalhos mentais sugeridos pelo sistema 1. Dentre esses atalhos estão:

- comportamento de manada: optamos pelo que achamos que a maioria optou;

- autoconfiança excessiva: decidimos não fazer nada agora porque no futuro daremos conta da questão; 
- status quo: decidimos pela primeira opção, pela mais fácil, ou deixamos as coisas como estão;

- aversão à perda: escolhemos a opção que envolva pouca ou nenhuma perda.

Conforme afirmam os autores, tomadores de decisão não o fazem em um vácuo. As pessoas fazem suas escolhas dentro de um contexto e também são influenciadas por ele. Se a criação desse contexto leva em consideração um conjunto de informações, temos um bom sistema de arquitetura de escolhas e, assim, podemos empurrar as pessoas para melhores decisões.

Uma pesquisa recente também realizada na Universidade de Chicago - The behavioralist goes to school: leveraging behavioral economics to improve educational performance - revelou que alunos esforçam-se mais quando seu desempenho está condicionado à perda do que quando está associado ao ganho de um incentivo (aversão à perda). Esse é apenas um exemplo do que a arquitetura de escolhas pode fazer pela educação. Thaler e Sunstein abriram o caminho. Resta aos pesquisadores das duas áreas aventurarem-se de mãos dadas nesse trajeto rumo a uma escola mais eficiente.

\section{REFERÊNCIAS}

THALER, Richard H.; SUNSTEIN, Cass R. Nudge: o empurrão para a escolha certa: aprimore suas decisões sobre saúde, riqueza e felicidade. Rio de Janeiro: Elsevier, 2009.

LEVITT, Steven D. et al. The behavioralist goes to school: leveraging behavioral economics to improve educational performance. Disponível em: <http://www.nber.org/papers/ w18165>. Acesso em: 26 jun. 2012. 